\title{
METAPSICOLOGIA DO PERDÃO
}

José Luiz Caon*

SÍNTESE - O autor serve-se de dois textos de Sófocles, Édipo-Tirano e Édipo em Colono, e de dois textos de Freud, $O$ chiste e sua relação com o inconsciente (1905c) e O humor (1927d). Extrai dos textos de Sófocles uma prefiguração da noção de autoperdão e, dos textos de Freud, elementos de uma metapsicologia do autoperdão. O texto freudiano de 1927 aprofunda e amplia a concepção de sobreeu. Assim, é mais que uma instância de aparelho anímico cruel, severa, tirana, intolerante e inclemente. Eu e sobreeu podem associar-se segundo o modelo da identificação paterno-filial e, desta aliança, surgir o humor, como uma construção auxiliar (Hilfskonstruktion) para levar a existência sem maiores temores para o eu. Segundo o modelo deste pacto, o autoperdão, relaçāo intrapsiquica, é condição necessária para uma relação interpessoal perdoante. Sem aquela, essa é vazia. Não é perdoando ao outro que se é perdoado, é perdoando-se que se pode até perdoar o outro. Assim sendo, a culpa, mal menor que a mortificação narcisista, mantém a inflamação do eu que, para se manter na posição de poder e de causador do "mal" no mundo, inflige-se autocastigos e reparações infindáveis e impossiveis. Diferentemente, com o autoperdão o eu associado ao sobreeu mantém a divida de gratidão, não aceita $\circ$ esquecimento e recusa a denegação.
ABSTRACT - The author utilizes texts, Oedipus the King and Oedipus at Colonus from Sophocles, and Wit and its relation to the uncontious (1905c) and Humour (1927d) from Freud. From the first texts, the authors derives a prefiguration of the notion of autopardon, and from the two others, he indicates some elements for a metapsychology of autopardon. Freud's 1927d text presents a more profound and more extensive conception as superego. It is more than a cruel, severe, tyrant, and pitiless instance of the psychic apparatus. Ego and Superego can associate according the model of a paternal-filial identification. From this alliance, autopardon, a intrapsychic relation, is a necessary condition for a forgiving interpersonal relationship. This one is empty without that one. It is not by forgiving the other that one is forgiven. It is forgiving oneself that one can even forgive the other. So, guiltness feeling, an inferior tribulation than the narcisistic mortification, maintains ego infatuation. In order to maintain itself in the position of power and origin of discontentment in the world, the ego inflicts in itself by means of superego endless and impossible reparations. Differently, the ego associated with the superego maintains the gratitude obligation, it doesn't accept forgetfulness and refuses denegation.

\section{Introdução}

"Feliz o que perdoa aos outros e o que se perdoa a si mesmo" (Borges). "Se, de fato, o sobreeu é quem no humor fala de maneira tão carinhosa e consoladora

* Instituto de Psicologia da UFRGS. Psicanalista.

\begin{tabular}{l|l|l|l|l|l} 
VERITAS & Porto Alegre & v. 43 & $\mathrm{n}^{0} 1$ & Março 1998 & p. 81-90
\end{tabular}


ao eu amedrontado, isso nos adverte que temos muitíssimo que aprender sobre a essência do sobreeu" (Freud, 1927d).

A metapsicologia da culpa é abundantemente desenvolvida nos textos da pesquisa psicanalítica. Em contrapartida, se nós nos interessarmos por uma metapsicologia do perdão, constatamos que dela quase só encontramos muita falta. Sem dúvida, falta perdoável, pois o perdão é assunto do ser homem. E "ser homem, adverte Pitigrilli, já é por si só uma circunstância atenuante".

Cabe ao leitor decidir-se ao longo e após a leitura desse texto protréptico se Pitigrilli tem razão. A protréptica são exercícios de desestabilização da doxa, opinião cimentada em amor de transferência ou anacrônico. A protréptica é intervenção didática utilizada por grandes mestres como Platão, Aristóteles e, ultimamente, por Jacques Lacan. Por meio dela, eles acordam o ouvinte ou leitor, sacudindo-o do sono consolador. Platão e Aristóteles desenvolveram-na utilizando o diálogo. Lacan utilizava o excurso em seus seminários. Sirvo-me da comparação. Assim introduzirei algumas noções da metapsicologia do perdão.

Apresento, em primeiro lugar, uma ilustração ou prefiguração do perdão, a partir de dois textos de Sófocles. Depois, em segundo lugar, para expor os inícios de uma teorização psicanalítica do perdão, tomarei dois textos de Freud.

Considero Sófocles prefiguração do pesquisador psicanalítico. Esse trágico grego mostra-nos, em duas obras trágicas, o destino de Édipo. Na primeira, ÉdipoTirano, ${ }^{1}$ apresenta-nos meridianamente a devastação da culpa patológica inconsciente (ánous). É o tributo do Narciso Triunfante, mas jamais triunfador. Na segunda, Édipo em Colono, sugere-nos pacificação e alegria de Narciso Derrotado, encontrado com sua verdade.

Outrossim, considero o analisante modelo do pesquisador psicanalítico. Essa posição enfrenta certos problemas. Por exemplo, Freud não foi analisante, em sentido estrito, de nenhum psicanalista. Então, como tomá-lo para modelo de pesquisador psicanalítico? Alem disso, se para ser psicanalista é necessário padecer pessoalmente uma psicanálise dirigida por um psicanalista, e se para ser pesquisador psicanalítico é necessário ter passado pela experiência da fundação da experiência psicanalítica, da qual a pesquisa psicanalítica é efeito e refundação, então como entender Freud como psicanalista e como pesquisador psicanalítico?

Respondo a essa questão, recordando que, no campo da psicanálise, todos nós temos precursor. Entretanto, Freud não teve precursor. Ele foi precursor de si mesmo, quer como psicanalista, quer como pesquisador psicanalítico. A formação do inconsciente, em atalho, ou no lance, formou o psicanalista precursor e o pesquisador psicanalitico precursor. A formação do inconsciente, no relance, forma psicanalistas e pesquisadores psicanalíticos. Assim como não haverá outro Sócrates, mas haverá sempre socráticos até a extinção da maiêutica, assim também não haverá outro Freud, mas haverá sempre freudianos até a extinção da psicanálise.

A - Examinarei, agora, confrontando brevemente os dois Édipos de Sófocles. Fá-lo-ei apenas no sentido de abrir uma ilustração para o tema de minha pesquisa psicanalítica sobre a metapsicologia do perdão.

1 A língua grega usa os substantivos basilêus e tyrannós que, via de regra, são traduzidos indistintamente por "rei”. Essa indistinção funda uma impropriedade. 
1 - Édipo-Tirano. A estrutura do enredo é realmente preciosa em termos de simetrias. Há um rei e uma rainha, Laio e Jocasta, de um lado, e um rei e uma rainha, Pólibo e Mérope, de outro. Nenhum desses casais tem filhos. O primeiro casal, tendo concebido, deseja saber o destino do primogênito. $O$ oráculo da pitonisa anuncia que o menino matará o pai e desposará a mãe. O pai, querendo evitar o destino nefasto, livra-se do recém-nascido ainda sem nome. Manda que o servo ceife a vida da criança e, como prova do cumprimento da ordem, lhe traga o cutelo ensangüentado. O servo obedece ao senhor, mas a compaixão o comove e é vencido pela piedade. Ao invés de sacrificar o infante, abre-lhe sulcos nos tenros pés. Ensangüenta a faca e leva-a para exame de seu senhor.

O outro servo, sabendo da infertilidade do casal de seus senhores e da existência desse menino recusado e abandonado pelos pais, acerta-se com o primeiro servo e leva o menino para os novos pais. Estes nomeiam o adotado: "Édipo, o de pés inchados".

O menino torna-se um jovem. Nada sabe de suas verdadeiras origens, mas pressente um destino obrando sob o destino que lhe é patenteado. Adolescente e curioso, busca, por sua vez, a mesma pitonisa que lhe profere o mesmo oráculo proferido aos pais que a tinham procurado: "Matarás o pai e desposarás a mãe." Édipo, que toma como pais a Pólibo e Mérope, foge horrorizado de tão funesto destino e abandona-os. Assim, pelo ato de evitar a horrenda perspectiva anunciada, parricídio e incesto, o jovem, fugindo do destino, caminhará na direção do infortúnio que pretendia evitar. Como sabemos, Édipo matará Laio e desposará Jocasta e com ela terá filhos.

Entretanto, entre o parricídio e o incesto, houve um duelo de vida e de morte. A esfinge, senhora dos mistérios e dos segredos, lança ao jovem, o enigma: "Quem é que de manhã anda com quatro pernas, ao meio-dia com duas e à noite com três?" Sabemos que Édipo responde acertadamente: "É o homem". E, assim, derrotado o monstro dos segredos e dos enigmas, ao ser lançado para o abismo, lança-lhe de volta, a Édipo, um outro e derradeiro enigma, contundentemente aproveitado por Pasolini em seu filme, Édipo-Rei: "O abismo para o qual me empurras não está noutro lugar senão dentro de ti."

Eis o homem! De todos os seres não é ele aquele que é essencialmente racional? Em que o diminui compartir da animalidade com os irracionais, se ele é racional? Édipo-tirano, Narciso Triunfante vitorioso escandaliza-se arrogantemente com os absurdos que ele mesmo realizou. Atribui-os a outro. Sanciona, com os piores castigos e com as mais cruéis penas, o próprio crime de parricídio seguido do próprio crime de incesto, como se fossem de outro.

Sófocles faz Tirésias dizer: "[...] Que terrível coisa não é o saber, quando esse saber não tem nenhum préstimo para seu sabedor. Eu bem que o sabia, [...]". De que serve ao homem esse saber que não se sabe, esse saber cuja essência é ser não sabida pelo homem, mesmo quando está cheio de racionalidade ou presunção? O verso 873 faz o coro dizer: Übris fitêuei túrannon, que a prova do estrangeiro, com diferentes sabores, transforma em "a petulância engendra o tirano"; la démesure enfante le tyran; insolence breeds the tyran; genera la superbia, il tirano. 
A Übris, em termos metapsicológicos, é raiz de toda culpa psicopatológica ou sofrimento que o homem padece para se subtrair a outro sofrimento: mal menor que distrai o homem sem subtraí-lo de mal maior... Ao invés da mortificação do narciso onipotente derrotado, a ferida infindavelmente pustulenta do narciso culposo triunfante.

2 - Édipo em Colono. Não é difícil ver que Édipo em Colono, de Sófocles, é Sófocles mesmo. Observemos que, em toda obra literária, personagem e autor equivalem-se em muitos aspectos, Entretanto, em Édipo em Colono, personagem e autor caracterizam-se por uma equivalência que excele: ambos encontram-se, frente a frente, com a própria identidade de ser.

Édipo lá em Colono, dobrando-se à inexorabilidade de sua história, desvenda o destino fundante do humano. Sófocles lá em Colono, sua terra natal, ressignificase, consome-se e rende-se ao trespasse.

No verso 393, é-nos mostrado, com sábia ironia, que a identidade do homem, enquanto ser, emerge precisamente lá onde o desejo irreversivelmente não mais vale:

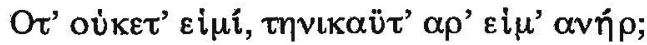

Por um lado, submetendo o verso quatro vezes à prova do estrangeiro, o leitor descobre nuances que permitem entendimentos de outra forma dificilmente divisados dessa identidade tímida e hesitantemente proposta por Sófocles:

\footnotetext{
Quando eu não mais existir, serei então verdadeiramente um homem?

C'est donc quand je ne suis plus rien, que je deviens vraiment un homme.

When I am nought, in that hour, then, I am a man?

Ridotto un nulla, ora sarei potente?
}

Por outro lado, essa sábia e irônica interrogação serve ao pesquisador psicanalítico desvendar, uma vez mais, a irrecusável e nunca solucionada oposição entre desejo e ser. Essa oposição entre homem-desejo e homem-ser mostra que 0 homem que trata de todos os seres, talvez, ele mesmo, ser não seja.

Ele mesmo, homem, paradoxalmente, ser não é? De fato, não está ele sempre a desejar ser isso ou aquilo? Como tal, o homem-desejo somente chegará a ser homem-ser quando parar de desejar, quando a mão da morte sobre ele se abater? Isto é, somente quando for despojado daquilo que o carateriza, a saber, o desejo, é que o homem se torna definitiva e irreversivelmente ser?

Édipo em Colono desgarra-se de um saber de sobreeu cruel, severo e tirano, de julgamento inquisitorial sem contraditório, como se diria na linguagem processual juridica. Despoja-se desta identidade exigente que o manteve no poder de se responsabilizar por ações que cometeu aos olhos do Ser, mas padeceu aos olhos do Desejar Ser. É desmedida transformar o foro externo em foro interno, seja em nome do direito ou em nome de qualquer moral, seja em nome de qualquer democracia ou em nome de qualquer teocracia.

Em Colono, Édipo mortificado, Narciso Derrotado, acede ao reino dessas verdades reveladoras de que, sendo senhor no seu reino, não é senhor em sua própria casa. Sófocles fá-lo dirigir-se ao Coro: 
ÉDIPO: Causei a minha desgraça, amigos! Causei a minha desgraça, mas foi involuntariamente. Seja a divindade testemunha de que não sou responsável disso! (p. 95)

CORO: De quê?

EDIPO: A cidade prendeu-me a um malfadado leito, sem eu saber; enredou-me numas calamitosas núpcias.

Depois, clamando reconhecimento de verdades penosamente buscadas ao longo de grande padecer, páthei máthos, ou aprendizagem pelo sofrimento, personagem e autor, Édipo em Sófocles e Sófocles em Édipo, demandam uma diferenciação fundante entre o que é destino e o que é decisão e escolha, entre o que é imposição inelutável e e o que é construção de alianças e pactos, ou simbolizações. A citação é longa, mas necessária:

"ÉDIPO: Que desavergonhada ousadia!... Quem julgas tu ultrajar com tua insolência? É às minhas cãs ou a ti próprio, que contra mim vomitaste da tua boca assassinatos e núpcias - calamidades, que, malgrado meu, sucederam para minha desgraça! Na verdade, assim aprouve aos deuses, irritados talvez contra minha casa, desde tempos antigos. Pois em mim não encontrarás crime algum a censurar, por causa do qual aquelas calamidades tenham vindo sobre mim e sobre os meus.

Diz-me: se um oráculo fez saber a meu pai que ele seria morto às mãos dos filhos, como poderás, com justiça, atribuir-me a culpa a mim, que do pai e da mãe não havia ainda recebido o germe da vida e não tinha, então, vindo à luz? Se depois, tendo nascido para minha desgraça, nas circunstâncias em que nasci, entrei a brigar com o pai e, sem conhecimento do que fazia nem de quem era meu adversário, o matei, que direito tens tu para censurar esta involuntária ação?

Atrevido! Não te envergonhas de me obrigar a falar das núpcias de minha mãe, tu que foste o seu irmão? Falarei, pois, delas rapidamente, porque não posso calar-me, depois de tu dares início a este discurso infame.

Ela foi quem me deu à luz; ela era minha mãe (ai, quão desventurado sou!), sem que eu nem ela o soubéssemos; e, depois de me ter dado o ser, foi para sua vergonha mãe de meus filhos! Mas uma coisa sei ao certo: é que tu difamas-me a mim e a ela de prepósito; enquanto que eu desposei-a contra minha vontade e contra minha vontade falo destas coisas. Mas não! Eu não serei difamado por essas núpcias, nem por causa da morte do pai, que não cessas de me atirar à cara como um insulto cruel.

Senão responde-me a esta única pergunta: se alguém inesperadamente se apresentasse aqui com intenções de te matar (a ti, homem justo!), porventura informar-te-ias primeiro, se esse tal era teu pai ou vingar-te-ias logo? Eu julgo que, se a vida te é cara, punirias o criminoso, sem te alongares em ponderações, se isso era ou não contra a justiça.

Em tal desgraça cai eu próprio por determinação dos deuses; mas creio que o espírito de meu pai, se ele voltasse à vida, nada teria a replicar-me por esta causa. Tu, porém, porque não és honesto e pensas que tudo se pode dizer, tanto o que é conveniente, como 0 que não o é, por isso é que me diriges tais ultrajes na presença destes."

Essa apologia pro vita sua dirigida a Creonte é uma prefiguração do que é a coragem de perdoar-se a si mesmo e, dessa posição, demandar o devido reconhecimento.

B - Assim como tomei Sófocles para extrair uma figura ou ilustração para minha pesquisa sobre a metapsicologia do perdão, tomo, agora, como modelo e procedimento, o percurso que encontramos em dois textos de Freud, aparecidos, respectivamente, em 1905 e em 1927. São Der Witz und seine Beziehung zum Unbewussten (Freud, 1905c) e Der Humor (Freud, 1927d). 
1 - Freud, 1905c. No fim do seu livro sobre os chistes (capítulo VII, sessão 7 e 8.), Freud faz uma breve incursão metapsicológica do humor, confrontando-o com cômico e o chiste. Diz que

"[...] o humor é um recurso para obter prazer apesar dos afetos penosos que o estorvam; introduz-se no lugar desse desenvolvimento de afeto, substitui-o. Sua condição está dada diante de uma situação em que de acordo com nossos hábitos estamos tentados a desprender um afeto penoso, e eis que aí influem sobre nós certos motivos para sufocar esse afeto in statu nascendi" (AE, VIII, p. 216).

Pelo humor, o paciente de afetos penosos tira partido do inelutável. Seu eu, não se associa ao tirano que o tortura (sobreeu) por causa da tortura, um exercício funesto do poder. Associa-se ao tirano por causa de outra forma de exercício do poder do tirano. Tanto a tortura quanto a magnanimidade revelam o poder do tirano! Somente súditos imbecilizados suportam a imbecilidade dos tiranos. Somente um eu culposo precisa da crueldade do sobreeu. Um eu que se faz humor e ironia seduz o sobreeu tirano sem destituí-lo. Humor e ironia do eu para com ele mesmo "desculpa" o sobreeu tirano e libera-o do exercício tirano de seu poder.

Freud ainda nos diz em sua pesquisa sobre o humor que

"[...] seu processo [do humor] completa-se numa só pessoa, a participação de outra não lhe agrega nada de novo. Posso reservar-me o gozo do prazer humorístico nascido em mim, sem sentir-me forçado a comunicá-lo" (AE, VIII, p. 216).

O humor é assim um processo de relação intrapsíquico. Esse processo ficará mais bem evidenciado com a teoria das instâncias psíquicas do aparelho anímico introduzidas alguns anos antes do aparecimento do trabalho de 1927. A comparação do processo defensivo com o processo do humor clareia um e outro. Por exemplo:

\begin{abstract}
"Alguma notícia sobre o deslocamento humorístico obtém-se quando o consideramos sob a luz de um processo defensivo. Os processos de defesa são os correlatos psíquicos do reflexo de fuga e têm a missão de prevenir a gênese de um desprazer que proceda de fontes internas, no cumprimento desta tarefa servem ao acontecer anímico como uma regulação automática que, é verdade, resulta ser daninha à seqüência e, por isso, é preciso que seja submetida ao governo do pensar consciente" (AE, VIII, p. 220-221).
\end{abstract}

A própria conclusão de Freud, no último parágrafo do Der Witz und seine Beziehung zum Unbewussten, aponta para uma síntese precisa para cada um dos três campos estudados, a saber, o chiste, o cômico e o humor, tomados comparativamente. As três modalidades de atividade anímica são marcadas por uma poupança de gastos que redunda em prazer. Nos chistes, o prazer surge de uma poupança no gasto com a inibição; no cômico, o prazer emerge de uma poupança no gasto com a representação e, no humor, o prazer provém de uma poupança no gasto com o sentimento. Freud remata dizendo:

"Nessas três modalidades de trabalho de nosso aparelho animico, o prazer provém de uma poupança. As três modalidades recuperam um prazer da atividade anímica que, na verdade, fora perdido por causa da própria complexificação dessas atividades. $\mathrm{O}$ bem-estar que conseguimos obter através dessas três modalidades é um estado de ânimo duma 
época em que pouco gastávamos com nossa atividade anímica. Era o estado infantil quando ignorávamos o cômico, éramos incapazes de chistes e não precisávamos do humor para sentir-nos felizes em nossas vidas" (AE, VIII, p. 223).

Uma metapsicologia ou teoria psicanalítica do perdão trata do autoperdão. O autoperdão é um bem-estar mental que emerge da economia não gasta com autorecriminações de um eu que se presume tão poderoso e onipotente quanto o de ser capaz, como Édipo-Tirano, de realizar, por conta própria e premeditadamente, um destino do qual não pode se subtrair. A descoberta da morte como conseqüência de doença, definhamento e velhice mortifica o eu que somente conhece a finitude como conseqüência de violência externa. É mais cômodo, para o eu onipotente, induzir-se a crer num castigo da divindade provocado por uma ação desse eu, do que ressignificar-se com a finitude, termo de existência final tão elementar como o termo inicial de existência.

2 - Freud, 1927d. Der Humor é um texto curto, tem somente 14 parágrafos. Strachey nos conta que, segundo Jones, Freud escreveu o texto em cinco dias, na segunda semana de agosto de 1927, para ser lido, pela filha Anna Freud, no X Congresso Psicanalítico Internacional, ocorrido em $1^{\circ}$ de setembro desse mesmo ano, em Insbruck. A meu ver, o texto comporta três méritos.

2.1 - O primeiro mérito do Der Humor constitui-se no fato de ser, teoricamente, um passo qualitativo na concepção da pesquisa psicanalítica. $O$ humor ultrapassa o modelo de sobreeu considerado como originador da culpa psicopatológica inconsciente. O humor dá-se além da dívida impagável, do esquecimento ou da denegação. Diferentemente da neurose e da psicose que, de uma forma ou outra, negam a realidade, suprimindo-a, o humor também nega a realidade, mas sem suprimi-la. Dissipa o mal-estar do rancor revoltado do processo neurótico e da indiferença ineficaz do processo psicótico.

"A superioridade da apreciação da realidade feita pelo humor contrasta flagrantemente com a inferioridade da apreciação da realidade feita pela neurose e pela psicose. $O$ humor não é resignado, mas rebelde. Significa não apenas o triunfo do ego, mas também o do princípio do prazer, que pode aqui afirmar-se contra a crueldade (desfavorabilidade) das circunstâncias reais" (AE, XXI, p. 158-159).

As duas características - die Abweisung des Anspruchs der Realität (rechaço da exigência da realidade) e die Druchsetzung des Lustprinzips (imposição do princípio do prazer) aproximam o humor aos processos regressivos encontrados na psicopatologia. Assim, como defesa contra a possibilidade de padecimento (Abwehr der Leidensmöglichkeit), o humor ocupa um lugar ao lado dos grandes métodos, como neuroses, psicoses, perversões, por exemplo, embriaguez, fuga de si, êxtase, etc., empregados pelo aparelho anímico para se subtrair do inevitável padecimento e sofrimento da vida.

O humor, outrossim, tem uma dignidade que 0 chiste não tem. Este, na verdade, ou serve para a obtenção de um ganho de prazer, ou para colocar essa obtenção a serviço da agressão. Freud pergunta-se assim: 


\begin{abstract}
"Em que, então, consiste a atitude humorística, atitude por meio da qual uma pessoa se recusa a sofrer, dá ênfase à invencibilidade do ego pelo mundo real, sustenta vitoriosamente o principio do prazer - e tudo isso em contraste com outros métodos que têm os mesmos intuitos, sem ultrapassar os limites da saúde mental?" (AE, XXI, p. 159).
\end{abstract}

Partindo dessas aproximações, o humor concebido segundo a metapsicologia freudiana, constante no percurso dos textos freudianos, é modelar para tentarmos uma metapsicologia do perdão. Por um lado, sabemos que o modelo da formação do sonho pode ser considerado modelo da pesquisa psicanalítica, no sentido de suspensão da censura, e que o modelo da formação do chiste também pode ser considerado modelo da pesquisa psicanalítica, no sentido de inclusão da alteridade. Por outro lado, o livro dos erros, ou da psicopatologia cotidiana, é uma ilustração de "serendipidade", isto é, de descobertas aparentemente casuais com que conta o pesquisador psicanalítico. Entretanto, o pesquisador psicanalítico, cujo campo de pesquisa são processos psiquicos fundantes e inamoviveis, como o são as relações intrapsíquicas do eu e sobreeu, não precisa supor que a pesquisa psicanalítica dos constituintes últimos da alma humana sejam um labor penoso, um tripalium, enfim, uma versão atéia da versão medieval de um mundo feito de vales (leia-se também tickets) de lágrimas.

2.2 - O segundo mérito constitui-se no alargamento da concepção do sobreeu, atribuindo-lhe outras possibilidades que não poderiam ser supostas a partir de uma concepção de sobreeu severo, cruel e tirano, isto é, constituído em juiz implacável e surdo, incapaz de ser acessado pelo acusado, pois que este não teria nem o direito de abrir a boca para se pronunciar (AE, XXI, parágrafos 12-14).

2.3 - Como terceiro mérito, podemos encontrar nesse texto, uma forma de conceber a pesquisa psicanalítica como uma dessas diversões poderosas que nos permitem tirar partido da desgraça cotidiana da vida, isto é, transformar o estorvo em pedra fundamental para a construção de um cotidiano suportável (erträglich) e conciliável (verträglich).

É no segundo capitulo de Unbehagen in der Kultur (Freud, 1930a), que Freud, citando a famosa paisagem de Goethe, deduz, sob influência desse, estratégias de levar a vida com menos descontentamento. O Wer Wissenchaft und Kunst besitzt, hat auch Religion; Wer jene beide nicht besitz, der habe Religion! $!^{2}$ de Goethe, transforma-se, na apropriação de Freud, em três construções auxiliares (Hilfskonstruktionen) para levar a existência. A ciência é dessas poderosas distrações que nos ajudam a minimizar a miséria cotidiana. O humor, é uma atividade animica, embora não científica, que minimiza a miséria cotidiana, sem denegá-la. Curiosamente, no texto de 1927, Freud é bem mais profundo em termos de sobreeu do que no texto de 1930. Em relação ao estudo do sobreeu, o texto de 1930 parece uma regressão e até um abandono de hipóteses mais profundas e abrangentes tomadas em 1927! É o que se pode perceber com a leitura paralela dos dois textos.

2 "Aquele que tem ciência e arte, tem também religião; o que não tem nenhuma das duas, que tenha religião!" (Zahme Xenien, IX: Gedichte aus dem Nachlass). 


\section{Algumas determinações}

Da oposição, segue a determinação, é um axioma da metapsicologia freudiana. Humor e perdão, em oposição e confrontação, permitem extrair algumas elucidações.

O humor pode realizar-se na pessoa mesma. É o auto-humor. O perdão pode realizar-se na pessoa mesma. É o autoperdão. Auto-humor e autoperdão são processos intrapsíquicos. O perdão, metapsicologicamente determinado, não é uma relação interpessoal, mas um processo intrapsíquico. Sem esse, aquela é vazia. Não é perdoando o outro que se é perdoado, mas perdoando-se que se pode até perdoar o outro.

O humor situa o sujeito simultaneamente na identificação paterna (Vateridentifizierung) e filial, pois que "se mediante o humor o sobreeu quer consolar o eu, não contradiz com isso que sua procedência seja da instância paterna" (AE, XXI, p. 162).

Se, como afirma Freud, "o humor é a contribuição ao cômico pela mediação do sobreeu", então o sobreeu não pode ser considerado apenas circunscrito no referencial do severo, do cruel e do tirano. Assim, podemos atribuir um caráter valioso ao humor, "esse prazer pouco intenso, que sentimos como particularmente emancipador e enaitecedor".

A confluência entre o eu e o sobreeu estabelece uma associação tal entre eles que, às vezes, é difícil separar um do outro. $\mathrm{O}$ isolamento entre um e outro geralmente dá-se em detrimento do eu. Entretanto, a via do auto-humor e do autoperdão são meios de beneficiar o eu associado ao sobreeu.

Podemos considerar o humor como uma poderosa diversão científica assim como a ciência como uma poderosa diversão humoristica: "Vejam, esse é o munđo que parece tão perigoso. Um jogo de meninos, ótimo para fazer brincadeiras com ele" (AE, XXI, p. 162). Como se disse, pelo o humor, então pelo autoperdão, não suprimimos a dívida impagável, não nos entregamos ao esquecimento, nem caímos na denegação. Mas, podemos levar a vida... como por exemplo, perante o mito mil vezes do pecado original, milhares de vezes revisitado.

Houve um tempo em que o eu defrontou-se com a morte natural ou finitude decorrente do definhamento, da velhice ou da doença. Ferido em sua onipotência, por essa peste, prefere explicar-se como causador e introdutor desse "mal", no mundo. Entretanto, antes dele, a finitude não se abatia sobre os dinossauros? Para manter-se no caminho da onipotência, o homem, Édipo-Tirano, pagará o pedágio da culpa, por crime que não cometeu. O autoperdão, como Sófocles em Colono nos mostra, é um humor benfazejo. De fato, o auto-humor, o autoperdão e a medicina afirmam e prolongam a vida. A culpa, a onipotência mágica e desmedida, essas negam a morte. E, no meio dessas duas posições, o homem ora hesita, ora se diverte, ora se culpa. Ser homem, então, é mesmo por si uma circunstância atenuante? 


\section{Referências bibliográficas}

BORGES, J. L. Fragmentos de um evangelho apócrifo. In: Elogio da sombra (poemas), Perfis (um ensaio autobiográfico). 4. ed. Porto Alegre: Globo, s.d. p. 51 (n. 8).

FREUD, S. Obras completas. Buenos Aires: Amorrortu, 1992. v. 8 e 21.

SÓFOCLES, Tragédias do ciclo tebano. Versão do grego, prólogo e notas por Dias Palmeira. Lisboa: Sá da Costa Editora, 1957.

SOPHOCLE. Tome I: Ajax, Oedipe Roi, Électre. Texte établi par Alphonse Dain et traduit par Paul Mazon. Paris: Belles Lettres, 1989.

- Tome III: Philotècte, Oedipe à Colone. Texte établi par Alphonse Dain et traduit par Paul Mazon. Paris: Belles Lettres, 1974.

SOFOCLE. II mito di Édipo, Edipo Re, Edipo a Colono, Antigone. Traduzione e note di Domenico Ricci. Milano: Biblioteca Universale Rizzoli, 1951.

SOPHOCLES. The plays of Sophocles. Translated into English Prose by Edward. P. Coleridge. Great books of the western world. London: Encyclopaedia Britannica, $23^{\text {rd }}$ Print, 1980. 